\title{
TOWARD A COGNITIVE SEMIOTICS
}

\author{
Per Åge Brandt ${ }^{1}$
}

\section{From structural to cognitive semiotics}

There are many ways to think of meaning and the possibility or impossibility ${ }^{2}$ of studying it. One way was characterized by the Swiss philosopher Elmar Holenstein, in an interview by R. Benatti ${ }^{3}$ :

The central concepts of cognitive science are all semiotic concepts (representation, symbol, information, code, program etc.) or imply semiotic concepts (computation). When cognitive scientists define themselves by proclaiming that they deal with Physical Symbol Systems, it is only a historical accident that one does not speak of semiotic science but of cognitive science. From a phenomenological point of view, it is a lucky accident because cognition is not exclusively logically and symbolically structured ${ }^{4}$.

1 University of Århus.

2 The unanalyzability of meaning is claimed by 'meaning scepticisms' or 'language scepticisms' which need not spring from general scepticism but instead be rooted in physicalistic naturalization programs, cf. K. HVIDTFELT NIELSEN, Interpreting Spinoza's Arguments - Toward a Formal Theory of Consistent Language Scepticism: Imitating Ethica, New York, The Edwin Mellen Press, Studies in Linguistics and Semiotics, vol. 15, 2003.

3 R. BENATTI, "Interview", Scripta Semiotica, vol. 1, 1992, pp. 133-150.

4 Ibid., p. 143.

Recherches en communication, $\mathrm{n}^{\circ} 19$ (2003). 
Semiotic concepts include traditional cognitive concepts, but from a phenomenological point of view, human cognition should also be approached by other semiotic concepts than those concerned with symbolic logic and purely symbolic representations, such as the semiotic concepts of iconicity (characteristic of imagery) and of indexical forms (characteristic of dynamic schemas). Holenstein is probably the first scholar to suggest the designation Cognitive Semiotics for a preferential project in contemporary research on meaning ${ }^{1}$. Being himself a specialist in Edmund Husserl and Roman Jakobson, he has trained and inspired younger British philosophers like Kevin Mulligan, Barry Smith, and Peter Simons, who have then based their thinking on a phenomenological realism linking cognition and semiotics. This line of thought and research has long been influential in Danish semiotics and was substantially consolidated during the last decade. In this article, I wish to mention yet another influential contribution to the shaping of 'semio-cognitive' thinking and analysis of meaning, namely what may be considered a Latin contribution.

In Europe and Latin America, a broad interdisciplinary school ${ }^{2}$ of structural semiotics, centered in Paris and Bologna, emerged in the 'structuralist' 1960ies and stayed influential well into the 1990ies, before eventually losing its impetus in a new academic context of deconstructionist or hermeneutic relativism and nominalism. Structural semiotics was an interdisciplinary, research-oriented, theoretical enterprise which advocated a view of cultural analysis and theory as a generalized linguistic project. It addressed the humanities in general and aimed at finding general or universal structures of meaning behind particular cultural and social, indeed preferentially aesthetic, manifestations of expression-borne contents - from texts to gesture, music, painting, architecture and so forth. The main principle was the idea that stable patterns of meaning could be found across occurrences of apparently unstable and context- and mediabound 'significations'. Meaning could thus be seen as grounded in a

1 Ihid.

2 The group of researchers gathering around professor A. J. Greimas is representative of this tendency in semiotics, cf. H. PARRET \& H.-G. RuPrECHT (eds), Exigences et perspectives de la sémiotique. Recueil d'hommages pour Algirdas Julien Greimas, I Aims and Prospects of Semiotics. Essays in honor of A. J. G., I - II, Amsterdam, Philadelphia, John Benjamins, 1985 and M. ARRIVÉ \& J.-C. Coquet (eds), Sémiotique en jeu. A partir et autour de l'euvre d'A. J. Greimas, Paris, Amsterdam, Philadelphia, Hadès-Benjamins, 1987. 
structurally stable semiotic 'competence', efficient across variations in 'performance'. Hence, in the predominant Parisian version ${ }^{1}$, the notions of stratification, generativity, transformations, and most importantly, of a surface structure superimposed upon a deep structure -all terms reflecting the vocabulary of generative grammar of the 1960 ies $^{2}$ - became keystones of this semiotic theory "... a vocation scientifique" (scientifically committed). A 'deep structure' of meaning ${ }^{3}$ would be a constitutive instance at a grounding level, a structuration of thinking proper, or of pure imagining, bound to be expressed and manifested through a process of concretizing transpositions or translations, sometimes called 'conversions'. A 'surface structure' of meaning would then represent and manifest this 'deep' meaning in a modified version, restructured and adapted to the circumstances of present communication, i. e. contextualized, by the process of derivation. Surface meaning would be a translated -transformedversion of deep meaning. It would contextualize the underlying, context-free thinking ('meaning-production') involved. The expressed and expression-bound meaning (the surface content) was seen as a circumstantial translation (transposition, transformation, or conversion) into some form of verbal discourse or some non-verbal semiotic system, of an underlying, non-discursive meaning (deep content).

Ontologically speaking, a surface structure would be pragmatic, i. e. functionally determined, whereas a deep structure would be semantic, i. e. functionally undetermined but cognitively constitutive as elementary ideation, thinking, and thus only determined by the universal design of the formats of 'meaning production', in other words: of cognitive conceptualization. Here is where the cognitive motif enters the picture.

Methodologically speaking, the surface structure of an utterance in some semiotic system would be immediately accessible to the consciousness of the semiotic subject whose inner 'cognizing' it

1 Cf. A.J. Greimas \& J. Courtés, Sémiotique. Dictionnaire raisonné de la théorie du langage, I, Paris, Hachette, 1979.

2 In this European perspective, Noam Chomsky was often regarded as an American structuralist. This view vanished rapidly when cognitive linguistics emerged in the 1980s.

3 Notice that this use of the generative terminology: 'deep' and 'surface' structure, 'transformations' etc., do not technically reflect their use in generative grammar. Instead they reflect the structuralist view of stratification in meaning. I tend to see this historical state of affairs as a case of fruitful misunderstanding. 
would translate and express, or to the consciousness of the subjects who interpret it (including the structural analyst), whereas the deep structure would remain hidden, less or not at all accessible to consciousness in real time, and only accessible post festum, through structural analysis. The 'surface meaning' would thus be phenomenologically given to the utterer and the addressee, and to everybody else around, whereas the 'deep meaning' were to be made explicit and phenomenologically manifest by some special techniques of structural analysis ${ }^{1}$.

The central concern of this form of thinking consisted, of course, in analyzing and applying structural models. 'Formalizations' including Saussurean oppositions, Greimasean squares, graphic diagrams and sequential formulae of different kinds, were elaborated and suggested as technical models in this sense, as analytical prompts guiding the approach to this core object of structural semiotics: the (deep) meaning of (surface) meaning. - How were the results of analysis verified, one may ask. The answers given were not always clear, but the general epistemological style of structuralism ${ }^{2}$ prevailed: since the deep meaning of an occurrence is an event of thinking and therefore must be intelligible per se, once it is discovered and made explicit, it can therefore in principle be experientially grasped and compared to its surface version; and if the latter can reasonably be understood as an avatar of the former, the analysis is considered more valid and plausible than if not. Thus, conscious experience will 'verify', validate, the analyst's hypotheses on 'non-conscious meanings's. Once verified in this sense, a result gives rise to predictions of similar results in occurrences otherwise related to the one in question, and if those are obtained, the validity of the first result is again strengthened.

I In communication, subjects would not even need to access the deep structures that determine their surface structures, since meaning survives the contextualizing transpositions. This idea might be one of the most valid 'generativist' contributions to an actual model of the process of meaning-production.

2 Cf. C. LÉvi-Strauss, Anthropologie structurale, I, II, Paris, Plon 1958, 1973.

3 What happens to an explicitated meaning that the analyst verifies, whereas the community of its 'surface' utterers and interpreters rejects it? The structural analyst will have to maintain its validity, and to declare its use 'unconscious' - the reby intending that its users have special reasons for not acknowledging it, not that it is in principle unaccessible to their consciousness. An epistemology must face ideology, in order to avoid relativism. 
These principles of stratification and phenomenological verification by explicitation and comparison are elementary in structural research on meaning. They need no justification in a 'generativistic' universalism ${ }^{1}$, but instead -I think- they deserve attention as reasonable ontological and methodological suggestions for a less restricted project studying meaning in an evolutionary perspective. They are practically common to all forms of research on meaning, including historiography. And they are strikingly analogous to the general principles of cognitive semantics. Conceptual metaphor $^{2}$, conceptual integration ${ }^{3}$, conceptualization in general, including so-called 'ception' (to avoid the alternative per- / con-) in the linguistic work on closed-class meanings by L. Talmy ${ }^{4}$, and the schematic explorations of grammar by R. Langacker ${ }^{5}$ - these and many other concept-oriented forms of analysis and theory likewise consist in suggesting models of meaning structures that do not occur immediately to 'cognizing' or communicating subjects, but can be modelled and thereby be made explicit and phenomenologically present to analysts and to 'cognizing' subjects, who will then be able to compare them to the immediate meanings of the analyzed occurrences, and who will then evaluate their plausibility as cognitively given meanings underlying their immediately experienceable translations. A cognitive structure of meaning is in fact a deep structure in the sense of structural semiotics ${ }^{6}$. But the status of 'depth', which is no longer generative in the historical sense, has to be specified.

I intend to show how these principles of a 'stratified phenomenology' can then help us elaborate an adequate theoretical framework for the study of cognition, culture, and communication.

1 There are even reasons to believe that linguistic syntax is the only semiotic field where they are not relevant: one, and the most important, may be that syntax in language is to be found exclusively at the level of semiotic surface structure.

2 Cf. G. LakofF, Woman, Fire, and Dangerous Things. What Categories Reveal about the Mind, Chicago-London, University of Chicago Press, 1987.

3 Cf. G. FAuCONnIER \& M. TURNER, The Way We Think. Conceptual Blending and the Mind's Hidden Complexities, New York, Basic Books, 2002.

4 Cf. L. TAlmY, Toward a Cognitive Semantics, I \& II, Cambrige, Mass., M.I.T. Press, 2000.

5 Cf. R.W. LANGacker, Foundations of Cognitive Grammar, I \& II, Stanford, Stanford University Press, 1987, 1991.

6 The terminological problem involved is that cognitive semanticists apparently have to avoid all terminological references to generative grammar, and therefore cannot appropriately clarify their epistemological position by explicit critical work. 


\section{Dynamic intermezzo}

In the 1980ies, some branches of structural semiotics and semiolinguistic semantics' were influenced by the works of the mathematician and philosopher René Thom ${ }^{2}$, who had seen a relation between mathematical topology, biological forms, and semiotic (deep) structures. Thom's catastrophe topologies were interpreted as models and applied in semiotic analysis, both in terms of 'actants's translating grammatical constituents and verb meanings, in terms of logical formats transcribing Greimasean 'square' models, and as dynamic representations of the modal-verb meanings ${ }^{4}$ formerly studied by Greimas and -in the Californian cognitive semantics- by Talmy and Sweetser, who had explored various modal and causal models of 'force dynamics', or of 'forces and barriers'. Since the Thomian inspiration originated in epistemological problems of biology, mathematics, and natural science in general, it inherited realistic philosophical habits of thinking and contributed to an epistemological 'naturalization' of the semiotic framework. Meaning was already seen as 'deeper' than its manifested phenomenon; now it was more drastically separated from language and discourse, and conceived as grounded in the biological nature, i. e. the cognitive neurobiology of the human mind. Here, meaning is what happens in the naturally prestructured mind of persons when they actively or passively perceive or conceive some entity, or when such minds

1 Cf. W. WILDGEN, Archetypensemantik. Grundlagen für eine dynamische Semantik auf der Basis der Katastrophentheorie, Tübingen, Gunter Narr Verlag, 1985; IDEM, De la grammaire au discours. Une approche morphodynamique, Bern, Peter Lang, Series European Semiotics, 1999; J. Petitot-Cocorda, Morphogenèse du sens. Pour un schématisme de la structure, Paris, Presses Universitaires de France, 1985; IDEM, Physique du Sens. De la théorie des singularités aux structures sémionarratives, Paris, Éditions du CNRS, 1992; P. ̊. BRANDT, La charpente modale du sens. Pour une sémio-linguistique morphogénétique et dynamique, Amsterdam/Philadelphia/Århus, John Benjamins \& Århus University Press, 1992; IDEM, Dynamiques du sens, Århus, Århus University Press, 1994; IDEM, Morphologies of Meaning, Århus, Århus University Press, 1995.

2 Cf. R. THOM, Stabilité structurelle et morphogenèse. Essai d'une théorie générale des modèles, Reading, Mass., W.A. Benjamin Inc. 1972; IDEM, Apologie du logos, Paris, Hachette, 1990.

3 The term stems from the French linguist Lucien Tesnière, cf. L. TESNIÈrE, Éléments de syntaxe structurale, Paris, C. Klincksieck, 1965.

4 Cf. P. Å. BrandT, La charpente modale du sens, op. cit. 
communicate, in the sense that their owners express something and 'mean' what they express (which is the case if the expressed content is after all -across all transpositions- what these persons are thinking and intending to express, supposing that they are able to check and report if this is the case).

Traditionally, and particularly before its structural turn, semiotics had mainly been known as an auxiliary hermeneutic discipline mainly concerned with sign models appropriate for summarizing the shifting historical interpretations of occurring signs, preferably verbal. In this new perspective, not only the -quite trivial- sign model (signifier over signified [signifiant-signifié], or form-meaning pairings) and its philosophical problems ${ }^{1}$, all referring to communication and coding, but also the host of new challenging issues related to understanding consciousness, the human mind $^{2}$, the psychological mechanisms of attention and perception, categorization and memory, thinking and affect, intersubjectivity and empathy, embodiment and abstraction, were to be addressed, and the new debate over these issues was to contribute to reformulating the entire field and view of semiotics, optimistically intended as a natural science of meaning and culture. Semiotics, conceived as the scientific study of the entire meaning dimension in human cognition, communication, and culture, and no longer just as some discourse on discourse, or some circle-spinning hermeneutics of hermeneutics, consequently had to be reframed to a considerable extent.

However, it preserved an essential feature that came to distinguish it in the new disciplinary context: its specialization in the study of autonomous meaning, in the sense of conscious phenomena that are not only linked to or referring to perception, emotion, and behavior, or to neuro-physiological processes in the human brain, but also to meaning itself, to other meaningful ideas, as an autoreferential mecanism. Meaning in this sense of an autonomous ontological form of being is maintained as a mental (individual, private, or collective, shared) realm of events that establish mutual relations between

1 Cf. U. Eco, A Theory of Semiotics, Bloomington, Indiana Universty Press, 1976. This author has evolved substantially since that work was published, and is now intellectually close to the views of cognitive semiotics.

2 The best account of the entire field and its issues is given in a beautiful essay by the Canadian neuropsychologist and philosopher Merlin Donald (M. DonALD, A Mind So Rare. The Evolution of Human Consciousness, New York/London, W.W. Norton \& Co, 2001. 
themselves, that is, internal relations between contents in the human mind. Such relations grow and form networks from entity to entity in the 'inner phenomenology' of meaning as structured by metaphorical concepts, by mental spaces, by figurative and dynamic schemas, categories, and semantic domains': all over the human imaginary, relations and connections of different kinds are developed, established, and reinforced -maintained by symbolization both individually and collectively, i. e. both idiosyncratically and culturally, and their structural principles must therefore precede idiosyncrasy as well as cultural specificity.

The internal connections between mental contents - connections that our minds are able to hold, elaborate, and evaluate, before letting them determine our beliefs, behaviors, acts, or affective reactionsmust be organized according to general or perhaps universal, integrative and schematic principles, and we will have to find and study them. These principles are still far from being well identified, classified, systematically studied, let alone well understood, but a joint venture of cognitive semantics and dynamic semiotics is currently beginning at least to make the very task of developing this dimension of cognitive science explicit and to acknowledge its relevance. The resulting general project is presently becoming known to academia under the label ${ }^{2}$ of cognitive semiotics.

\section{What is symbolization?}

Cognitive semiotics thus considers meaning as such as its essential concern, and is prepared to interrelate semiotic relations established internally, between semantic contents by purely mental connectors, and those established externally, between expressed signs,

1 My current account of this panoply is given in P. $\AA$. BRANDT, Spaces, Domains and Meaning. Essays in Cognitive Semiotics, Bern, Peter Lang, Series European Semiotics, 2003 (in press).

2 A M.A. curriculum in Cognitive Semiotics has recently been established at the Center for Semiotic Research, University of Århus. Its general line of research is presented in the Danish anthology Kognitiv Semiotik (P. BUNDGAARD, J. EGHOLM \& M. Skov, Kognitiv semiotik. En antologi om sprog, betydning og erkendelse, Copenhagen, P. Haase og Søns Forlag, 2003). The preliminary title of this volume was "Dynamisk semiotik" [Dynamic Semiotics], since this was the label of the actual tendency in the $1990 \mathrm{ies}$, at a moment when the introduction of dynamic modelling was its most salient feature. 
or between signs and the acts they command or the neurophysiological (affective) states they report on ${ }^{1}$. It claims that the study of this 'semio-semantic' dimension of the cognitive project is crucial not only to an appropriate understanding of grand-scale communication and culture, but even to the most elementary microstudy of human thinking and feeling. If culture and cultural variation are natural phenomena, based on an individual capacity to create concepts, communicate them, and learn them from other individuals, then we urgently need to study the grounding phenomenon of 'shared cognition' given in intersubjective behaviors, such as cooperative work, exchange of services, goods, persons, information; and in pure dialogue. In such behaviors, individuals can indeed be said to 'share' meanings. The general explanation appears to be that intersubjectivity of meaning is based on these individuals' capacity to signify and to identify each other's signifying mode of interrelating contents and, on the grounds of identified interrelations, at least roughly (structurally: schematically), to further identify their elements.

Signifying meaning is probably only possible because of the relational 'essence' of meaning: what needs to be shown and picked up in thought and communication is the symbolic proximity of 'related' items. Symbolization ${ }^{2}$ is inherently syntactic; to symbolize is simply to connect within a frame and thereby create a syntax. We do not 'symbolize' ${ }^{3}$ items one by one, but by grouping, collocating, compounding things that do not otherwise 'belong together' and which must therefore be taken as 'symbols', precisely for this reason. In a sense, this principle of symbolic proximity is aesthetic: the functionally absurd collocation of objects within a frame is exactly what activates the intentional reference to meaning. Framing and intending are one and the same; the form called a frame induces the substance called intention. What is absurd per se can thus easily become meaningful par excellence $e^{4}$. It is even difficult to stop absurd configurations from being perceived as symbolically meaningful. They are meaningful because experienced as 'meant': in the eyes,

1 Brain, Meaning, and Behavior are seen as three equally important and interrelated topics and forms of reality.

2 Note that symbolization is in no way equivalent to or limited to the practice of symbolic logic.

3 In the sense of: ascribing socially significant, unpredictable and non-trivial abstract meanings to objects or forms.

4 This is, I suspect, the surrealistic origin of semiotic behavior, inherent in all forms of humor, from archaic to modern. 
ears, or hands of an observer, such collocations must be signified as 'thought out' by someone. The syntactic proximity of symbols in such a framed 'formula' is inherently connected to the relational essence of meaning: connecting things is connecting people. In our species, to connect things is, inherently, to think -not necessarily in the strong Peircean sense of finding solutions to problems, but in the broader and more playful sense of trying out combinations of imaginary contents- and to think-with-someone ${ }^{1}$. These imaginary contents arise directly from the compounded things in a way wellknown to all humans: framed things are lifted out of their singular mode of presence and are taken as representatives of their categories (tokens of their types), and when they are perceived as co-present in the same frame, their constellation is cognized as a syntactic phrase that utters something more abstract than the sum of these categories. Framing generates generic predication.

Language proper is not a necessary prerequisite of this 'semiogenetic' process, as it may have emerged through the evolution of our species and probably of other hominoids. Verbal language, including grammatical organization of meaning and an overall organization of phonetic and gestural signifying, evidently constitutes an interesting case of auditive symbolization, perhaps anticipated by some forms of music; the decisive advantage of verbal language, however, is twofold: its structural contrast between word and grammar makes it possible for users to form radically better, still more 'absurd', nontrivial, compositions, and thus to create intensely significant syntactic constellations. And the high reproducibility of its expressions multiply their saliency and significance, since it allows them to spread effortlessly over large groups of (already) communicating subjects and thus to be substantially reinforced and stabilized by an endless cultural broadcasting and feedback, creating a drastically enhanced semiotic coherence (and a corresponding 'ethnic'2 excitability) in a population.

Language evolves as a semiotic medium that lends itself to an apparently unlimited activity of translating from other modes of thinking and symbolizing. As all other semiotic modes or systems, language manifests an unsolvable dramatic conflict between unity,

1 The authorial plural 'we' is inherent in all symbolic behaviors.

2 'Ethnicity', collective idiosyncratic behavior, is probably just semiotic fine-tuning; it pays its price in the form of decreasing individual sensibility to people outside the 'ethnic' in-group. 
based on the presence of universal structural properties, and differenciation, tendencies to differ in structure whenever and wherever communicative attention is intense. The better it works, and the more refined it makes local communication, the weaker it makes general and global communication. Language exponentially blows up not only the intellectual potential of cognition but also the cultureforming potential of symbolization.

In this discussion, one of the remaining deep evolutionary questions is: how did we then learn to frame, and thus to symbolize? The answer to this question is still unfound, but there are strong reasons to believe that artistic, religious, and ritual activities are main sources of this crucial mental operation.

\section{A cognitive-semiotic model of culture}

The stratified view of meaning, inherited from structural semiotics, allows us to articulate the contextual and the noncontextual aspects of meaning. The relational view of symbolization further offers us an entry to the study of contextualization as a constitutive generator of culture and cultures.

In fact, the notion of context refers either to radically circumstantial specifications, such as the particular characteristics of individual participants and their interpersonal situation, or to generic specifications of thinking and acting such as those following from a genre of discourse or of practices in a given society of a certain type and marked by certain ethnic styles and notions, in short: culture. Our 'deepest' cognitive operations, such as causal linking, comparing events to each other, etc., are expressed in forms conditioned by nothing but our mind itself; but these operations are therefore contextually specified at two levels, first at this 'shallow' level of cultural editing, then at the 'surface' level of situational editing. The inverse process of interpretation extracts meaning-as-thinking from its situationally and culturally edited form, so to speak by subtracting these semiotic transpositions, i. e., by de-specifying it (cf. figure 1). 


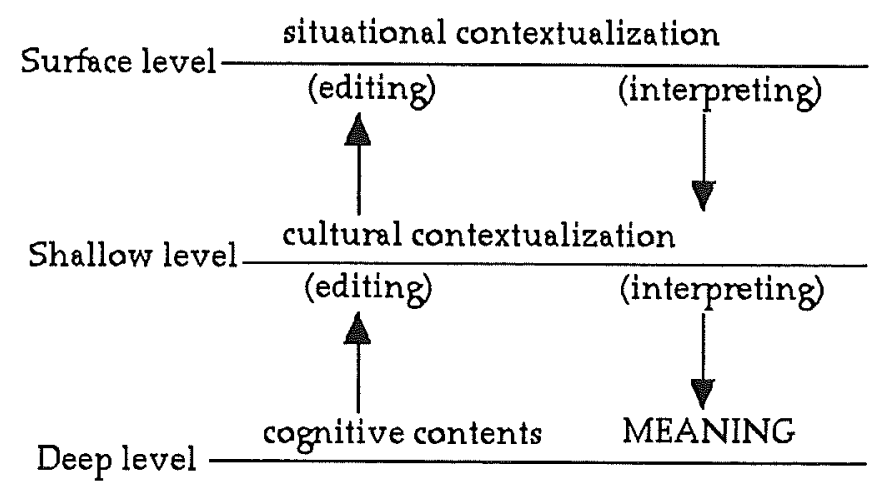

Figure 1: Cognitive semiotic stratification

It is a phenomenological fact that expressive communication through this process of editing and interpretation is felt as a natural context of cognitive activity. The 'cognizer' experiences his own 'making sense' as a production of meaning with other subjects (minds) that virtually or actually interpret his utterances. His mental contents are in this sense elements of meaning insofar as they stay recognizable through the entire intersubjective arch of edition and interpretation. The finality, we might say, of cognition is to yield shared meaning.

The cultural contextualization involves framing. Therefore it involves symbolic reorganization of the cognitive contents in question: a continuous flow of thinking has to be 'cut up' or condensed into syntactic wholes that can be contained within a finite frame. This process of syntactic editing and symbolic reshaping of an underlying imaginary event (an occurring representation of some referent) is probably related to what the cognitive research tradition calles embodiment. The gestural acting by which we can theatrically show to each other what we are thinking is in fact organized by a temporal staging as of a play, a fictive doing that makes it possible for our body to fill a role or a set of roles in some phrase accounting for the structure of a scenario. If this hypothesis is valid, then cognitive embodiment happens between the deep and the surface structures; which would explain why we do not necessarily find any embodied 
aspects in deep and abstract cognitive contents ${ }^{1}$, but always find cultural characteristics of situational expressions bound to their embodied manifestation, and par excellence in gesture.

It should be understood that the mental integrations that form the overall architecture of the human 'inner life', or imagination, will take place on the 'deep' level of the above model. The merging of sensory material into entities of multimodal perception and of these percepts into space-time 'worlds', that finally integrate in our affective configurations and our beliefs, all unfold as neuro-phenomenological processes that contexual determinations will further specify when they stabilize as meanings and then are memorized. The active function of memory and consciousness in our mental architecture cannot be adequately described in the perspective of integration only, but needs the view of cognitive semiotic stratification to be clarified. Contents have to be rendered reflexive, through edition and interpretation, at least virtually (by intersubjective simulation, as in inner speech), and thus to become meanings, in order to be memorized. To 'pay attention to' some object is to let this reflexivization happen.

It may be relevant to note, as a final remark, that the relation between objects and signs, in the ordinary sense of this term (aliquid stat pro aliquo), will turn out to be singularily close when considered in this framework: when objects are firstly cognized, they are integrated contents of consciousness, but when they are secondarily presented, virtually or actually communicated, they are seized by a reflexive attention and retention, and, through this transformation, have to become signs -signs of their symbolically given contexts, of the generic 'signifieds' or denotations hereby created, and as all signs, receptive to situational connotations.

The doctrine of signs will have to be revised thoroughly in the scientific context of cognitive semiotics. And the cognitive notion of semantics will have to be modified in the light of the strong communicative focus in this approach. However, the most important aspect of the research to be realized is its empirical commitment. In cognitive semiotics, language, art, human manifestations of meaning in general, are to be analyzed as found, whether experimentally or

\footnotetext{
1 I have argued elsewhere (P. A. BRANDT, "Mental spaces and cognitive semantics. A critical comment", to appear in Journal of Pragmatics, 2004) that cognitive semantics has long been inhibited by Spinozan notions and inappropriate antiCartesianism; the issue touched upon here is particularly sensitive to positions in this implicit philosophical debate.
} 
historically, rather than to be invented by the theoretician for the sake of illustration. This explicit empirical commitment is, I would suggest to think, the necessary prerequisite to the future development of a coherent theory of mind and meaning. 